\title{
DE BATENTES, VENEZIANAS, DOBRADIÇAS, VIDROS: MOLDURAS QUE ENQUADRAM SENSAÇÕES, FORMAS, SENTIDOS
}

From jambs, shutters, hinges, windowpanes: framing sensations, shapes, senses

\author{
Bianca Rosina Mattia \\ https://orcid.org/0000-0002-0136-1241
}

Elton da Silva Rodrigues

https://orcid.org/0000-0002-1890-7482

Isabele Soares Parente

https://orcid.org/0000-0003-0561-5488

Jair Zandoná

http://orcid.org/0000-0002-4301-9436

Tânia Regina Oliveira Ramos

http://orcid.org/0000-0002-2477-0419

Universidade Federal de Santa Catarina, Programa de Pós-Graduação em Literatura,

Florianópolis, SC, Brasil. 88040-900 - ppglitufsc@gmail.com

\begin{abstract}
Quem olha, de fora, através de uma janela aberta, não vê jamais tantas coisas quanto quem olha uma janela fechada. Não há objeto mais profundo, mais misterioso, mais fecundo, mais tenebroso, mais deslumbrante do que uma janela iluminada por uma vela. O que se pode ver à luz do sol é sempre menos interessante do que o que se passa atrás de uma vidraça. Nesse buraco negro ou luminoso vive a vida, sonha a vida, sofre a vida. Charles Baudelaire, Pequenos poemas em prosa, 2006, p. 211.
\end{abstract}

É assim que o conhecido poema em prosa "As janelas" de Charles Baudelaire inicia, convidando-nos para uma leitura mais atenta com relação às transformações da vida moderna. O olhar, nesse processo, talvez seja um dos mais recorrentes recursos que compõem a modernidade e a flânerie. Daí que o sujeito poético reflete sobre as diferenças existentes entre uma janela fechada e outra aberta, o que remeteria à nova condição de viver modernamente: tal como a pessoa que vê através dos vidros das lojas e dos cafés o espaço exterior, permitindo que penetre na vida alheia, adote - e não há como deixar de lembrar de "As multidões", outro poema baudelairiano - como suas as profissões, alegrias, 
misérias que a experiência possa lhe proporcionar.

Ainda sobre isso, para o poeta francês, admirador do trabalho de Constantin Guys (um artista que, segundo ele, aparentava estar em constante estado de convalescença), o ponto de partida do artista moderno está na sua curiosidade e na maneira como ele busca representar a beleza fugaz da vida daquele instante (BAUDELAIRE, 2010, p. 24) semelhante ao que é possível espreitar, de maneira fugidia aquilo que o olhar é capaz de alcançar à meia luz por uma janela de uma casa desconhecida.

Um passo atrás nessa viagem arquitetônica das - ou entre as - janelas temos o destaque desse enquadramento desde o título: A janela de esquina do meu primo, de $\mathrm{E}$. $\mathrm{T}$. A. Hoffmann (2010 [1822]), narrativa responsável por apresentar uma das primeiras tematizações literárias da cidade e sua realidade fugidia, realidade provisória/flutuante emblemática da (pós-)modernidade. O enredo se desenrola com a chegada do narradorpersonagem à casa de seu primo, responsável por ensiná-lo a distinguir as figuras, "no amontoado de gente se movendo num afã insignificante" (HOFFMANN, 2010, p. 16), entre a massa de passantes, que compõem a cena vista da praça do mercado em Berlim. A partir de sua privilegiada visão, a janela de esquina de sua morada, única forma que o primo convalescente - "essa janela é meu consolo, aqui a vida alegre ressurgiu para mim e eu me sinto reconciliado com o movimento incessante que me proporciona" (HOFFMANN, 2010, p. 13), registra - tem de acompanhar as transformações do cenário urbano:

Esse mercado, disse meu primo, é também agora uma imagem fiel da vida eternamente mutável. A atividade intensa, a necessidade momentânea, leva as pessoas a se reunirem; alguns instantes mais tarde tudo está deserto, silenciam-se as vozes que se misturavam e se confundiam num barulho desordenado e cada posto abandonado pronuncia de maneira extremamente vívida: acabou! (HOFFMANN, 2010, p. 57).

Como que em um salto entre uma janela e outra de um edifício, chegamos na Lisboa de inícios do século XX português. A cidade é a grande personagem que Fernando Pessoa explora, pelo olhar de Bernardo Soares, no seu Livro do desassossego. Escreve Soares: o "mais que há no mundo é paisagem, molduras que enquadram sensações nossas, encadernações do que pensamos." (PESSOA, 2011, p. 177). Sua visão tem morada, ponto de partida. O ajudante de guarda-livros está no $4^{\circ}$ andar e parte da "Rua dos Douradores para o Impossível..." (PESSOA, 2011, p. 79). É da janela de seu quarto que vê o mundo para ele a Rua dos Douradores é o mundo e onde se dedica à escrita nas horas vagas. Aliás, Soares escreve (n)o Livro sempre quando está cansado, depois de um dia de trabalho, em seu quarto:

Do meu quarto andar sobre o infinito, no plausível íntimo da tarde que acontece, à janela para o começo das estrelas, meus sonhos vão, por acordo de ritmo com a distância exposta, para as viagens aos países incógnitos, ou supostos, ou somente impossíveis." (PESSOA, 2011, p. 378).

Não é por acaso que o Livro do Desassossego tem como última morada essa rua, 
pois nela se encontravam os douradores, os profissionais responsáveis por gravar os elementos decorativos e textos nas capas das publicações luxuosas. Figurativamente, é com dourado que Soares gravava no grande livro sua vida: "tudo é rua na vida" (PESSOA, 2011, p. 345).

A janela de seu quarto se torna representativa, pois através dela pode divisar o que está em seu horizonte, como também o caminho inverso. A janela - semelhante às portas ou as pontes que podem levar para outra dimensão, mundo, ou realidade - leva-o a divisar o que está à sua frente, fazendo-o ver não a materialidade dos objetos contemplados, mas emoldura a dor que a cidade se reveste por meio de suas sensações. Para ele, o mundo é cheio de impossibilidades: que se desdobram em formas e cores sensacionistas. Soares vê e detalha no Livro, escrita que se aproxima ao seu ofício de contabilidade no armazém de fazendas (PESSOA, 2011).

Dessas janelas emolduradas literariamente, a espreitar as mudanças do mundo, como que em sintonia, a artista Ailê Gonçalves ${ }^{1}$ fotografou em 9 de abril de 2014 a imagem que abre este volume e tem como título "Atravessamento". Entre os significados possíveis está o congelamento para um pré-pandêmico da COVID-19. Das cartografias urbanas, capta nuances de um dos prédios do Centro de Comunicação e Expressão da UFSC. O findar de 2021 marca que há quase dois anos essas janelas estão fechadas. Tempos de trabalho remoto intenso. Apesar do desejo, ainda não é possível olhar de dentro para o mundo, pois a circular pelo lado de fora das janelas, invisível aos olhos, um vírus espreita nossa existência da forma mais cruel: "[...] é um pedagogo cruel, que não perde tempo explicando as razões do seu agir e simplesmente age como deve agir", elucida Boaventura de Sousa Santos (2021, p. 38) ao lançar mão da metáfora e propor uma possibilidade de futuro, da pandemia à utopia, em cuja leitura nos inspiramos para este editorial.

A metáfora do vírus como pedagogo convoca à aprendizagem não por outra via que a da escuta profunda, desafiadora porque inevitavelmente dolorosa, à necrolinguagem do vírus, conforme a leitura física e metafísica do tempo presente proposta por Santos (2021). "O vírus abre as veias do mundo [...] e revela com extrema agressividade todas as vulnerabilidades que marcam o dia a dia da grande maioria da população mundial. E não só as revela, como as faz sangrar ainda mais." (SANTOS, 2021, p. 103).

No cenário pandêmico, que é ainda drasticamente discriminatório e falsamente democrático, há formas de exclusão que se assumem como formas de destruição ontológica, sobretudo pela invisibilidade dos grupos que as sofrem, já antes considerados desnecessários, descartáveis, irrelevantes. Dentre essas formas, o sociólogo português destaca a que denomina senexista. Em suas palavras:

\section{Designo como senexismo (do latim senectus, "velhice") o preconceito contra}

\footnotetext{
1 Ailê V. Gonçalves, 30 anos, é formada em Letras/Português, com mestrado em Literatura tendo pesquisado sobre Imagem e Arquivo a partir de documentos fotográficos; realiza graduação em História, todos pela Universidade Federal de Santa Catarina (UFSC). Amante da fotografia, identifica sempre a potência da imagem como linguagem. Atualmente, é ilustradora da página @desterronankin, trabalho com o qual busca enaltecer a história e a cultura local.
} 
as pessoas mais velhas, um preconceito baseado na ideia de que o valor social e o prazo de validade social dos seres humanos estão associados à sua produtividade entendida em termos capitalistas. (SANTOS, 2021, p. 134).

Enredados pelos modos de dominação do capitalismo, do colonialismo e do patriarcado, não faltaram declarações e medidas adotadas por inúmeros governantes a escancarar o preconceito do senexismo durante a pandemia. Sem escrúpulos - e muito distante de qualquer altruísmo - a vida desse grupo de pessoas contou menos frente à economia, cujo efeito não poderia ser mais perverso: à medida que se reforçava a vulnerabilidade da população idosa, aumentava-se a confiança dos mais jovens em se sentirem imunes ao vírus, viabilizando-se uma série de atitudes que só fizeram proliferar o vírus e colocar em risco toda a sociedade.

O preconceito do senexismo, a reforçar opressões e hierarquias, a perpetuar e intensificar vulnerabilidades e formas de exclusão, aumenta a distância e a possibilidade de vida em comunidade entre as gerações. Como destaca Audre Lorde (2019), há diferenças que precisam ser corretamente reconhecidas e nomeadas e, sobretudo, seus efeitos em nosso comportamento. Dentre elas, a discriminação etária:

O "fosso entre gerações" é uma importante ferramenta social para qualquer sociedade repressora. Se os membros mais jovens de uma comunidade consideram os membros mais velhos como imprestáveis ou suspeitos ou excedentes, eles jamais serão capazes de dar as mãos e examinar as lembranças vivas da comunidade, nem fazer a pergunta mais importante, "por quê?". Isso provoca uma amnésia histórica que nos obriga a reinventar a roda toda vez que temos de ir comprar pão na padaria. (LORDE, 2019, p. 242).

A aproximação das gerações, traduzida no combate ao preconceito do senexismo e à discriminação etária, ao resgatar a diversidade comunitária da vida, pode conduzir a mudanças criativas, tão necessárias e urgentes para o tempo de agora. Foi - e ainda é para muitas e muitos - pelo lado de dentro das janelas, a convivência com filhos/as, netos/as, bisnetos/as, parentes, vizinhos/as e mesmo pacientes idosos/as, durante a pandemia, que ocasionou uma oportunidade de encontros e reencontros (por vezes, a distância) permeados de escuta, atenção, cuidados, afetos e enfrentamentos. Talvez um encurtamento entre a distância geracional, talvez um novo futuro sendo construído.

Mas há ainda outro espaço, que se imbrica e por vezes se confunde com o espaço da vida, onde aquela distância pode ser diminuída, novas linguagens podem ser compreendidas, outras formas de ver e sentir o mundo podem nos ser apresentadas: o espaço da arte. Neste vigésimo sexto volume da Anuário, publicado no decorrer deste ano, apresentamos um conjunto de artigos que se debruça sobre as Representações da velhice na literatura e outras artes, e o fazemos com o desejo de ressignificar esse momento em que novos laços e gestos de humanidade foram sendo construídos. Com este número queremos dar existência e resistência aos que se foram e aos que ficaram, chamados de 
grupos de risco e ameaçados de isolamento vertical, mães, pais, tias, tios, avôs, avós, professoras, professores, porque estivemos tão longe e tão perto buscando janelas da alma especialmente nas plataformas digitais, única possibilidade durante tanto tempo de exercícios de aproximação. Além desses, continuamos com a publicação da segunda parte do Dossiê Poéticas da Voz, organizado por Susan de Oliveira (UFSC) e Susana Souto Silva (UFAL), bem como de artigos de temática livre e resenhas.

\section{Referências}

BAUDELAIRE, Charles. Pequenos poemas em prosa. Trad. de Gilson Maurity Santos. Rio de Janeiro: Record, 2006.

BAUDELAIRE, Charles. Sobre a modernidade: o pintor da vida moderna. Belo Horizonte: Autêntica Editora, 2010. [Concepção e organização Jérôme Dufilho e Tomaz Tadeu].

HOFFMANN, E. T. A. A janela de esquina do meu primo. Trad. Maria Aparecida Barbosa. São Paulo: Cosacnaify, 2010.

LORDE, Audre. Idade, raça, classe e gênero: mulheres redefinindo a diferença. Trad. de Léa Süssekind Viveiros de Castro. In: HOLLANDA, Heloísa Buarque de. (Org.). Pensamento feminista: conceitos fundamentais. Rio de Janeiro: Bazar do Tempo, 2019. p. 239-249.

PESSOA, Fernando. Livro do Desassossego. 3.ed. São Paulo: Companhia das Letras, 2011. [Ed. Richard Zenith].

SANTOS, Boaventura de Sousa. O futuro começa agora: da pandemia à utopia. São Paulo: Boitempo, 2021.

\section{NOTAS DE AUTORIA}

Bianca Rosina Mattia (biancamattia@gmail.com) é doutoranda em Literatura no Programa de PósGraduação em Literatura da UFSC. Mestra em Literatura (PPGLit/UFSC). Licenciada em Letras-Língua Portuguesa e Literaturas de Língua Portuguesa (UFSC). Bacharela em Ciências Jurídicas e Sociais (UPF). Integra o quadro discente do Núcleo de Literatura Atual - Estudos Feministas e Pós-Coloniais de Narrativas da Contemporaneidade (LITERATUAL/UFSC). Compõe a Comissão Editorial da revista Anuário de Literatura.

Elton da Silva Rodrigues (eltonrodriguesdsr@gmail.com) é licenciado em Letras - Língua Portuguesa e Literatura pela Universidade Federal de Santa Catarina (UFSC, 2018) e mestrando em Literatura pelo Programa de Pós-graduação em Literatura da mesma universidade. Integra a equipe do Laboratório Floripa em composição transdisciplinar: arte, cultura e política (LabFLOR). Compõe a Comissão Editorial da revista Anuário de Literatura, periódico vinculado ao Programa de Pós-Graduação em Literatura da UFSC. Atualmente é professor de Língua Portuguesa na rede municipal de educação de Palhoça.

Isabele Soares Parente (isabele-soares@hotmail.com) é mestre em Literatura pela Universidade Federal de Santa Catarina. Graduada em Letras - Língua Portuguesa pela Universidade Regional do Cariri. É pesquisadora do Núcleo de Estudos em Teoria Linguística e Literária (NETLLI) e participa do Núcleo de Pesquisa em Cultura Popular Behetçoho. Compõe a comissão editorial da Revista Anuário de Literatura (PPGL/UFSC).

Jair Zandoná (jzandona@gmail.com) realiza estágio de pós-doutorado no Programa de Pós-Graduação em Linguística da UFSC. Doutor e mestre em Literatura pela mesma instituição. É um dos editores da Revista 
Anuário de Literatura (PPGL/UFSC) e editor de resenhas da Revista Estudos Feministas (REF). Integra o quadro de pesquisadores/as do Instituto de Estudos de Gênero/UFSC, do Literatual/UFSC e do Grupo de Estudos no Campo Discursivo/UFSC.

Tânia Regina Oliveira Ramos (taniareginaoliveiraramos@gmail.com) é Professora titular da Universidade Federal de Santa Catarina, coordenadora do nuLIME - Núcleo de Literatura e Memória. É uma das editoras da Revista Estudos Feministas e da Anuário de Literatura. Atua nas áreas de gênero e subjetividades, história e memória literária.

\section{Agradecimentos}

Não se aplica.

\section{Como citar esse artigo de acordo com as normas da ABNT}

MATTIA, Bianca Rosina; RODRIGUES; Elton da Silva; PARENTE, Isabele Soares; ZANDONÁ, Jair; RAMOS, Tânia Regina Oliveira. De batentes, venezianas, dobradiças, vidros: molduras que enquadram sensações, formas, sentidos. Anuário de Literatura, Florianópolis, v. 26, p. 01-06, 2021.

\section{Contribuição de autoria}

Elaboração e contribuição coletiva.

\section{Financiamento}

Não se aplica.

\section{Consentimento de uso de imagem} Não se aplica.

\section{Aprovação de comitê de ética em pesquisa}

Não se aplica.

\section{Conflito de interesses}

Não se aplica.

\section{Licença de uso}

Os/as autores/as cedem à Revista Anuário de Literatura os direitos exclusivos de primeira publicação, com o trabalho simultaneamente licenciado sob a Licença Creative Commons Attribution (CC BY) 4.0 International. Estra licença permite que terceiros remixem, adaptem e criem a partir do trabalho publicado, atribuindo 0 devido crédito de autoria e publicação inicial neste periódico. Os autores têm autorização para assumir contratos adicionais separadamente, para distribuição não exclusiva da versão do trabalho publicada neste periódico (ex.: publicar em repositório institucional, em site pessoal, publicar uma tradução, ou como capítulo de livro), com reconhecimento de autoria e publicação inicial neste periódico.

\section{Publisher}

Universidade Federal de Santa Catarina. Programa de Pós-Graduação em Literatura. Publicação no Portal de Periódicos UFSC. As ideias expressadas neste artigo são de responsabilidade de seus/suas autores/as, não representando, necessariamente, a opinião dos/as editores/as ou da universidade.

\section{Histórico}

Recebido em: 03/12/2021

Aprovado em: 06/12/2021

Publicado em: 13/12/2021 